\title{
Analysis on the Countermeasures of Optimizing Urban Tourism Public Service System under the Background of Smart City
}

\author{
Jianghong $M^{1}$ and Fei Ren $\mathbb{D D}^{2}$ \\ ${ }^{1}$ School of Tourism Management, Guilin Tourism University, Guilin 541006, China \\ ${ }^{2}$ School of Business Administration, Zhongnan University of Economics and Law, Wuhan 430074, China \\ Correspondence should be addressed to Fei Ren; 201701080022@stu.zuel.edu.cn
}

Received 31 December 2020; Revised 3 February 2021; Accepted 18 February 2021; Published 27 February 2021

Academic Editor: Wei Wang

Copyright (c) 2021 Jianghong Mo and Fei Ren. This is an open access article distributed under the Creative Commons Attribution License, which permits unrestricted use, distribution, and reproduction in any medium, provided the original work is properly cited.

\begin{abstract}
At present, there are problems in the construction of the tourism public service system such as poor coordination and coordination among various departments, lack of resource integration mechanism, and low level of information of tourism public services. Therefore, by analysing the problems existing in the tourism public service system in the context of smart cities, this paper puts forward strategies to optimize the tourism public service system. First, we build a smart tourism public service system platform for overall development and optimize the tourism public service platform. Secondly, by focusing on the behaviour of tourists, we construct a big data analysis and management system for the behaviour of smart tourism tourists. Finally, for the traffic situation in the process of tourism, a smart traffic line network based on pheromone ant colony is constructed. The results of the questionnaire survey on tourists show that the optimized public service system platform has achieved great satisfaction.
\end{abstract}

\section{Introduction}

China's tourism industry is undergoing a rapid transition from the period of mass travel to individual travellers. With the in-depth development of the tourism industry, individual tourists will gradually become the main body of the tourism consumer market $[1,2]$. The rise of the individual consumer market has changed the relationship between traditional tourism demand and supply. Tourists' demand for tourism information is increasing, especially the demand for tourism public service systems. The development of information technology, the integration of information technology, and tourism, especially the construction of smart city system, provides a more systematic, more convenient, intelligent, and humanization of ideas and means to solve the visitors access and application of public service. It has laid a solid foundation for the basis of tourism public service system construction under the background of intelligent city. In addition, it further promotes the construction of urban tourism public service system $[3,4]$.
Smart tourism is to use the Internet to allow tourists to interact with the scenic area in real time, making the information of the scenic area more transparent and the travel schedule more personalized $[5,6]$. Tourist attractions integrate tourism resources and tailor tourism products for tourists. With the help of terminal Internet access devices, tourists can arrange and adjust travel plans at any time, to achieve intelligent perception and convenient use of various types of travel information. There are relatively many foreign studies on the behaviour of tourists using public tourism services, including the search behaviour of tourists "information, tourists" demand preference, and satisfaction with services. Their research results are mainly concentrated on the process of obtaining and using tourist information research. San et al. [7] distinguished domestic and foreign tourists and studied the importance and cultural differences of services of tourist destination information. Ahmadimanesh et al. [8] emphasized the public information supply in the tourism management of government marketing decision support system. Li et al. [9] expounded the construction of the service system of destination tourism information from 
the perspectives of organizational structure and economic structure, information and data sources, quality control, and technology application. Wu et al. [10] introduced the tourism information service system, including transportation, climate, and other information services. Zhang et al. [11] introduced in detail the types, contents, and functions of free information provided by the US tourist information centre. They believed that the free travel information in the United States is rich in content, focusing on information updates, emphasizing the timeliness of information, the accuracy of maps, and copyright attributes. Zhu et al. [12] understood the concept of public tourism information service as a general term for tourism information services, such as information consultation and tourism information distribution, provided by government departments, public institutions, social organizations, and other organizations to tourists and the public at the destination. In order to meet the needs of tourists for tourism basic information, tourism product promotion information, tourism safety information, public environment, and other related information services, Li et al. [13] developed and processed information products and delivered them to tourists in a convenient way. Tan et al. [14] proposed the construction of a modern tourism information consulting service system with urban tourism information consulting service centre as the core, with various functions such as tourism orientation, consulting services, publicity and promotion, market research, image communication, and tourism shopping. Zhou et al. [15] proposed a public service system of tourism information from the four systems of tourism public information platform system, display system of tourism information, service system of tourism transportation, and consultation system of tourism information from the perspective of smart tourism.

Various aspects, such as the development level and technical level, restrict the public tourism service and application environment of the tourism industry, and the construction is relatively low. Therefore, its research will usually be based on the status quo and deficiencies and have some general recommendations. Ruan et al. [16] pointed out the problems existing in the tourism-consulting service centre through field visits and put forward corresponding constructive opinions from the aspects of institution construction, operation mode, service content, and development trend. Shen et al. [17] emphasized that tourism public information is the basis of tourism public services and believed that the government and enterprises should speed up the construction of the tourism public information service system, improve the online service system based on the tourism information website, and base on the tourism-consulting centre. The service window and audio service system cantered on the tourism service hotline make it a perfect public service system of tourism information covering different people and fields. Alfred et al. [18] developed a kind of information service function traditionally provided by tour operators and tour guides through research. Shigematsu et al. [19] discussed the construction and application of intelligent transportation systems from the perspective of improving the traffic flow at tourist destinations. Based on the value of global positioning services and web-driven technological innovation, Montealegre et al. [20] have studied the forms that influence the creation, exchange, and evaluation of tourism information, which will promote the formation of more convenient tourism models. Mehraliyev et al. [21] proposed a framework model of smart tourism that guides visitors to a convenient experience.

By analysing the problems in the tourism public service system under the background of smart city, this paper puts forward the countermeasures to optimize the tourism public service system. Specifically, it includes the construction of a smart public tourism service system for overall development, a big data analysis and management system for smart tourist visitor behaviour, and a public transportation service system for smart transportation. Finally, through a questionnaire survey of tourists, it is concluded that tourists have a higher evaluation of the optimized public service system than unoptimized.

The rest of this paper is organized as follows: Section 2 analyses related concepts and technologies of smart cities and smart tourism. Section 3 proposes strategies for optimizing the tourism public service system in the context of smart cities. Section 4 verifies this article through a questionnaire survey the effectiveness of the optimization strategy. Section 5 summarizes the full text and points out future research direction.

\section{Smart City and Smart Tourism}

2.1. Smart City. A smart city uses a new generation of information technology to manage the operation of the city in an integrated and systematic manner, allowing the various functions of the city to operate in harmony with each other, providing high-quality development space for enterprises in the city, and providing citizens with a higher quality of life. The city has become an all-round development city suitable for people. Smart cities need smarter city planning and management, more reasonable and adequate resource allocation, and urban environmental protection in place, can provide more job opportunities, have emergency response capabilities for emergencies, and have sustainable development capabilities. Smart city is not only a brand-new urban development concept, but also a new way of development, operation, and management. It uses cloud computing, mobile Internet, Internet of Things, artificial intelligence technology, data mining technology, and information processing technology as basic platforms. With the help of smart phones, smart computers, and other terminal facilities to collect and mine information, analyse, and organize real-time transmission. As shown in Figure 1, it is a smart city application. After real-time application to enhance the autonomy, intelligence, and interactivity of information collection, consumption decision, product purchase, arrival in the city, and all tangible or intangible processes arrive in the city, the ultimate goal of the smart city is to meet differentiation service makes it enjoy an impressive experience [22]. 


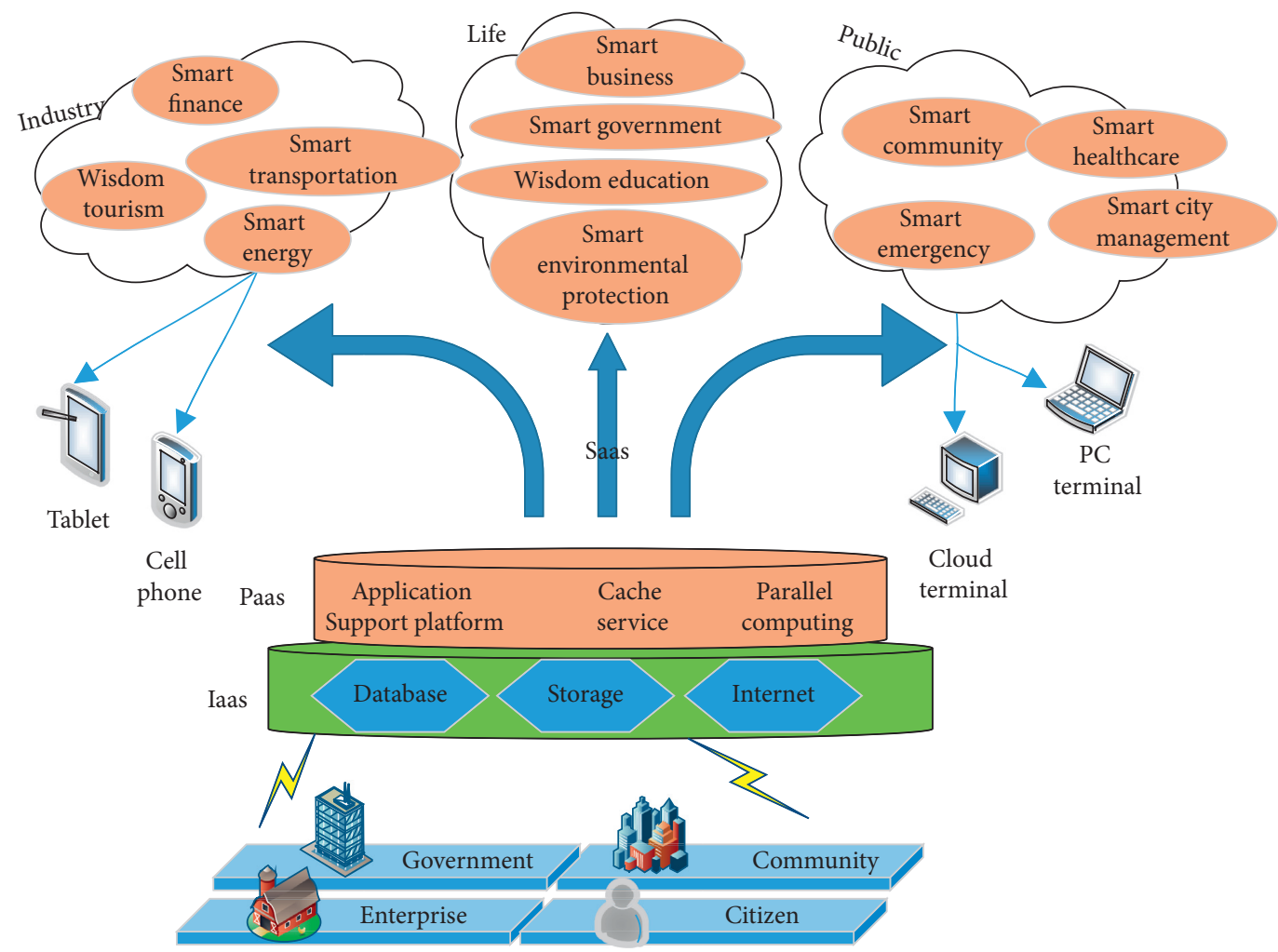

FIgURE 1: Smart city applications.

According to the summary of the development of smart cities at home and abroad, smart cities can be roughly divided into five types [23]:

(1) Industry-driven: it refers to an urban development path that takes high-tech information technology industry as the guidance and forms an intelligent industrial chain or industrial cluster as the core driving force.

(2) Innovation-driven: the innovation-driven path refers to the application of emerging information and network technologies, and the innovation system as the core, including smart city innovation subjects, innovation infrastructure construction, innovation talent system, and innovation resource environment.

(3) Sustainable development: the sustainable development path refers to the starting point of environmental protection and sustainable development of resources, to form intelligent management of environmental resources and to be rational, efficient, and reusable, and to create a sustainable development of environmental resource system and urban development path.

(4) Management service-driven: the management service-driven path refers to the use of technological means to upgrade, optimize, etc., to enhance public management service capabilities, making the city's public management functions more efficient, intelligent, precise, and convenient.

(5) Multiobjective development: the multiobjective development path refers to a development path formed by comprehensively considering factors such as the intelligent upgrading of industries, the improvement of public management services, the improvement of residents' lives, and the sustainable use of resources and environment during the construction of a smart city.

In addition, smart cities have the following characteristics [24]. First, the support of smart cities is the Internet, Internet of Things, mobile Internet, smart terminals, and other high technologies. Second, the basic purpose of smart cities is to provide information services to governments, city management departments, and city operators. Finally, the fundamental purpose of a smart city is to meet people's basic needs.

2.2. Tourism Public Service System. Tourism public service refers to the timely delivery of processed and developed information products to relevant tourists in a convenient way to meet the needs of tourists for basic information, product information, safety information, public 
environment, and other related information services of tourist destinations $[25,26]$.

Tourism public information service is the core part of the construction of the tourism public service system, which realizes the connection between tourism suppliers and tourism demanders, prompts potential tourists into real consumers, and can effectively enhance the tourist experience of tourists and improve tourist satisfaction, and improving services at tourist destinations are conducive to the development of the tourism industry.

Tourism public service quality is whether the public information services such as tourism products, information consultation, tourism orientation, product ordering, promotion, complaint and rescue, and security transportation are provided by the destination tourism-related institutions and enterprises through the tourism public information service platform or other facilities [3].

The essence of smart tourism refers to the application of smart technologies, including communication technology, in the tourism industry, with the goal of enhancing tourism services, improving tourism experience, innovating tourism management, optimizing the use of tourism resources, enhancing the competitiveness of tourism enterprises, and improving tourism modernization project of industry management level and expansion of industry scale.

It can be seen from this that the development of smart tourism will inevitably place higher demands on the construction of tourism public information services. Tourism public information service is the foundation of the development of smart tourism, the booster for the upgrading and transformation of the tourism industry, the support for the improvement of the level of tourism services, and the reliable guarantee for the harmonious development of regional tourism. The overall framework of the public service system for smart tourism is as shown in Figure 2.

\subsection{Problems in Tourism Public Service System in the Context} of Smart City. As the tourist spots scattered in the city are far apart, the service facilities that should be provided are not complete. For example, in the guidance system of tourist traffic, there are a small number of tourist attractions signs, guide maps of tourist traffic, traffic guidance signs, etc., and the standards are not uniform. Poor play, poor food, and poor accommodation have led to tourists visiting mostly for one-day or half-day trips. The bottom line is that under the current management system, various government departments cannot form synergy and lack unified planning and coordination, cannot effectively integrate tourism elements, have difficulty coordinating large industries, and cannot coordinate overall advancement of the tourism industry.

According to the survey, the online information service level of the tourism public information service platform is very low, the information update speed is slow, and the content coverage is insufficient. The lack of an electronic tour guide system has affected the access of tourists to information on attractions, tourist routes, and public facilities. The distribution of tourism-consulting service points is unreasonable and limited in number. The lack of popularization of tourist call centres has led to unblocked channels for tourists to defend their rights. Although it has a dedicated tourism, official websites work with many travel e-commerce companies (OTA). However, the official tourism website mainly focuses on the maintenance of tourism government information, and the actual travel information available to tourists is very small. In addition, there is a single type of cooperative OTA product. Moreover, mainly based on the sale of scenic spot tickets, leading to the diversified immediate needs of tourists is difficult to meet. This situation shows that the intelligence of travel consulting services needs to be improved.

At present, although tourism information centres have been set up in railway stations and most scenic spots, few tourists come to consult and the overall function is not perfect. Although the scenic area has a rest area in the visitor centre, it provides convenient tools such as baby carriages, wheelchairs, umbrellas, etc. and is specially equipped with barrier-free facilities and passages. However, there are many thresholds and steps in various scenic spots, the existing barrier-free passages are not smooth, and it is not convenient for special people to travel. There are too few rest facilities on the key roads in the scenic area. There is a lack of financial service facilities such as ATMs at the tourist hub. These circumstances illustrate the asymmetric supply of tourist public services and tourist demand. The reason for the problem is that the main supply department does not understand the real needs of tourists and lacks effective public participation channels. As a result, some tourism public service facilities are idle or in short supply, and it is difficult to achieve optimal disposal of resources.

\section{The Optimization Strategy of Tourism Public Service System under the Background of Smart City}

3.1. Building a Smart Tourism Public Service System for Overall Development. At present, the development of most tourism public services is not integrated with the construction of public services in the entire city. Therefore, taking the smart city construction as an opportunity, in the process of smart city construction, we will strengthen the special planning research in a targeted manner and incorporate the construction of the tourism public service system into the future economic and social development work planning and deployment. It is necessary to create a unified mechanism and open platform for the unified organization and coordination of various tourism-related departments in order to sort out and build a smart tourism public service system that can be developed as a whole. In this paper, the content of the tourism public service system is improved from the aspect of tourism transportation services. The specific design is shown in Figure 3.

As shown in Figure 3, according to the status and objectives of the construction of a public tourism service system, a unified tourism public service system platform is built using smart city construction as a carrier to form a unified service interface, authority management, user 


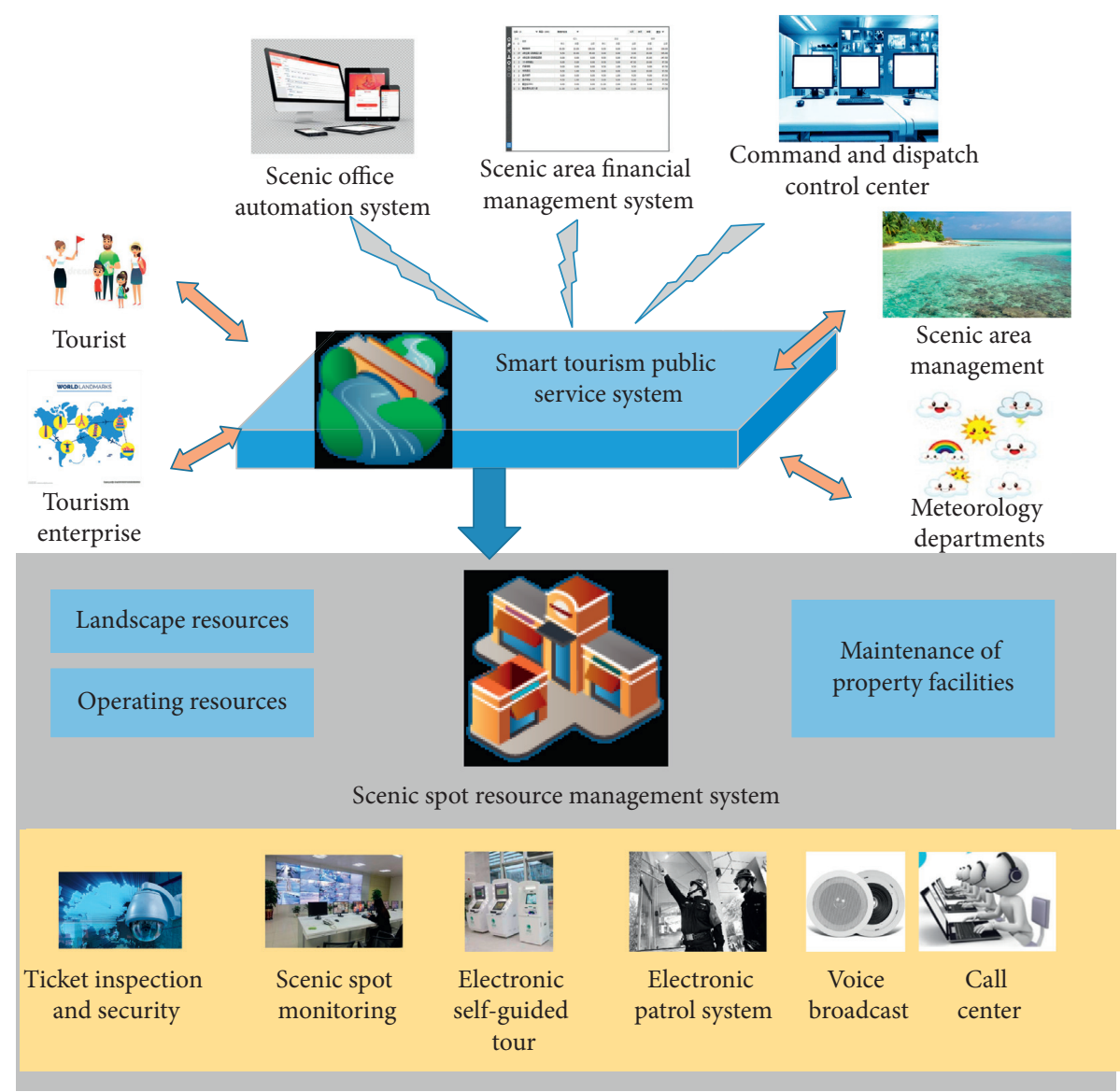

FIGURE 2: Overall framework of the public service system for smart tourism.

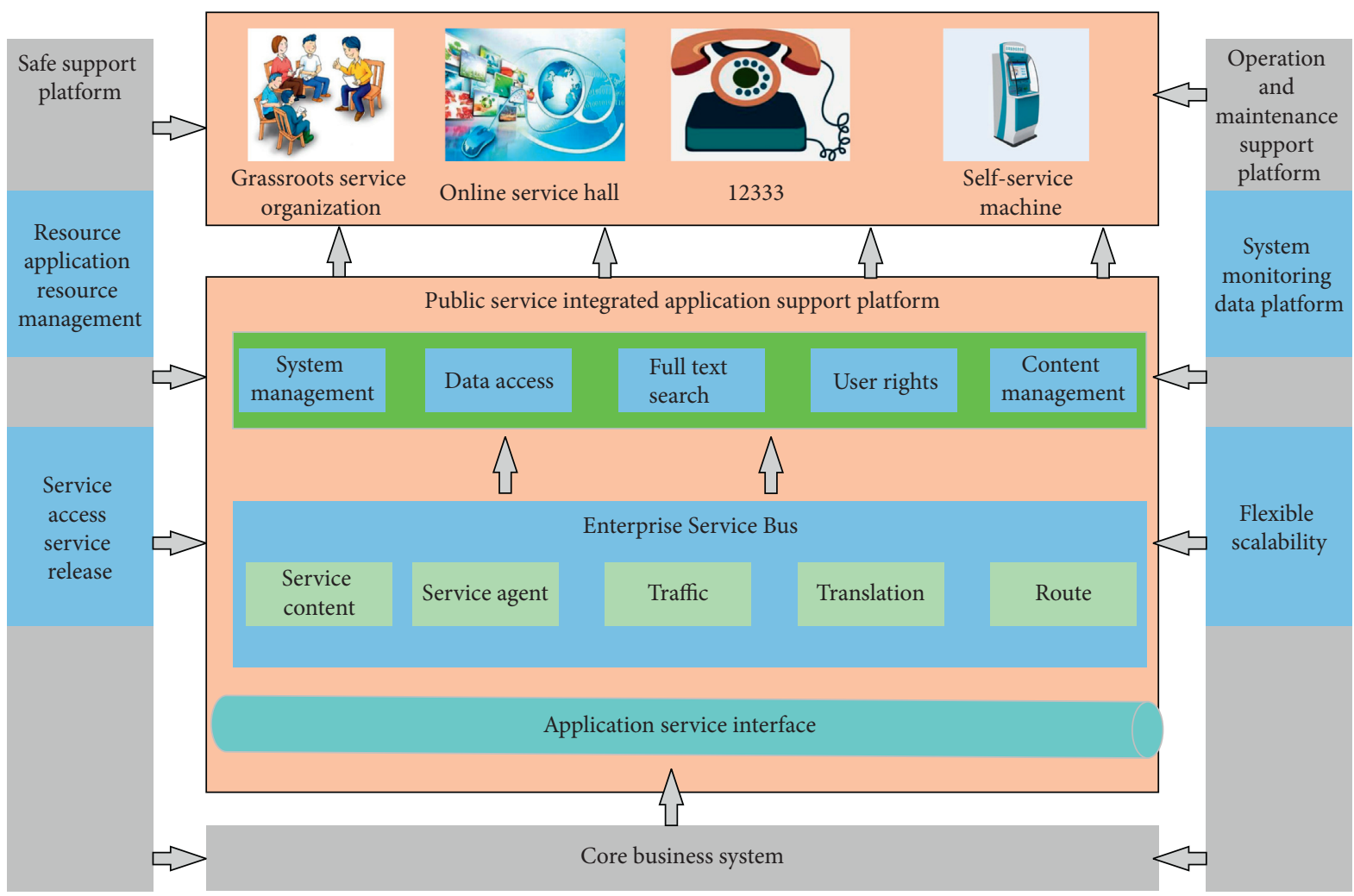

Figure 3: Design of a smart tourism public service system platform. 
management, and data management. Taking basic data of the tourism information system as resources, it integrates online service hall, self-service system, telephone consultation system, and grassroots management information system to build a multiform, multichannel, multilevel, and comprehensive public service platform. The platform calls the data resources through the service bus and finally realizes the service call, and it realizes data synchronization and business collaboration.

\subsection{Construction of Big Data Analysis and Management} System for Tourist Behaviour. Modern information technology is developing rapidly, and the Internet era has arrived. It has brought new challenges to all occupations and has spawned new formats. The tourism industry will also accelerate the integration and development of information technology and accelerate the transformation from traditional service industry to modern service industry.

In the Internet age, tourists' travel behaviour and ways of obtaining information are changing. Only after studying the needs of tourists, they can know what the government is going to do and what the enterprises are going to do. According to the statistical survey on the development of the Internet in China, as of June 2013, mobile phone netizens accounted for $78.5 \%$ of the total netizens. Relevant data reports show that $89 \%$ of Chinese tourists will obtain information through online media in the next year. This shows that the Internet has become the main channel for tourists to obtain information. In response to the problems of asymmetric public service supply and demand and low resource utilization, in the process of smart city construction, special seminars and public opinion surveys were conducted to timely grasp and understand the demand for local public residents and foreign tourists for tourism public services and establish participation mechanism. Information feedback is used as a reference basis for construction to achieve a balance between the supply and demand of tourism public services, thereby creating a system of benefiting the people and sharing convenience between hosts and guests.

As shown in Figure 4, the analysis of tourists' behaviour patterns can be divided into three stages, namely, before, during, and after the trip. The predeparture stage is a stage where tourists make consultations and make choices. This stage is mainly marketing for government enterprises, and smart tourism marketing is here. In the past, tourists' food, accommodation, travel, shopping, and entertainment were all done through travel agencies. Now, with the prevalence of Internet and free travel, many of them are realized through the Internet and mobile clients. This stage is the most important stage of smart tourism, that is, smart service. In the "post-travel" stage, tourists' sharing of travel experiences and complaints and so on must be realized through the Internet, and smart tourism must play a certain role.

3.3. Constructing a Smart Public Transportation Public Service System. The bus to the scenic spot in the city has low accessibility, lack of public bicycle rental points, few car rental companies, and no consideration of the needs of tourists. The location and distribution of parking lots in transportation infrastructure is unreasonable, and road conditions are congested. Traveling by tourists requires more time and energy, which is not conducive to improving the overall quality of life. The construction of intelligent transportation refers to the introduction of information technology into the traffic construction process, thereby reducing the phenomenon of vehicle congestion and saving the cost of travel time for tourists. Throughout the evolution of domestic and foreign urban transportation, the increase in private cars is the main reason for the traffic problem. By building transportation facilities with stronger bearing capacity and larger capacity, the urban transportation mode is gradually changed to meet public travel needs. The results of the survey are shown in Table 1 . The percentage of tourists choosing public transportation is 0.282 , the percentage of tourists choosing electric vehicles is 0.093 , the selection of private vehicles is 0.215 , the selection of taxis is 0.311 , and the selection of bicycles is 0.064 . The choice for hiking is 0.035 .

Road traffic routes have relatively long waiting times for passengers due to peak commuting times. Various mobile terminal public transportation inquiry systems have been opened. However, due to the lack of an intuitive image, the average number of people currently using the query system is only more than 30,000 people per day. Obviously, the usage rate is still low. Although the city has many main roads, the lack of expressways and branch roads is the main reason for frequent traffic jams and traffic safety accidents on the city's main roads. The significance of constructing intelligent transportation facilities is to help tourists understand the traffic situation in advance and adjust the travel routes in time, which can effectively reduce the time cost of travel for tourists.

The optimization problem of the urban transportation network is a classic optimization problem.

Let variable $m$ be the number of ant colonies, and $\tau_{i j}(t)$ represents the amount of information remaining on the $i$ to $j$ line at time $t$. At the initial moment, the amount of information on each path is equal. During the movement of ant $k$ according to the amount of information on each path, we determine the city to be transferred next. Variable $p_{i j}^{k}(t)$ means that ant $k$ is transferred from position $i$ to probability of $j$ :

$$
p_{i j}^{k}(t)= \begin{cases}\frac{\left[\tau_{i j}(t)\right]^{\alpha}\left[\eta_{i j}(t)\right]^{\beta}}{\sum\left[\tau_{i s}(t)\right]^{\alpha}\left[\eta_{i s}(t)\right]^{\beta}}, & j \in \text { allowek }_{k}, s \in \text { allowek }_{k}, \\ 0, & \text { otherwise. }\end{cases}
$$

As time goes by, the pheromone left on the path will gradually disappear. The parameter $\rho$ is used to indicate the degree of pheromone disappearance. After time $n$, the ant completes a cycle, and the pheromone on each path should be adjusted according to the following formula: 


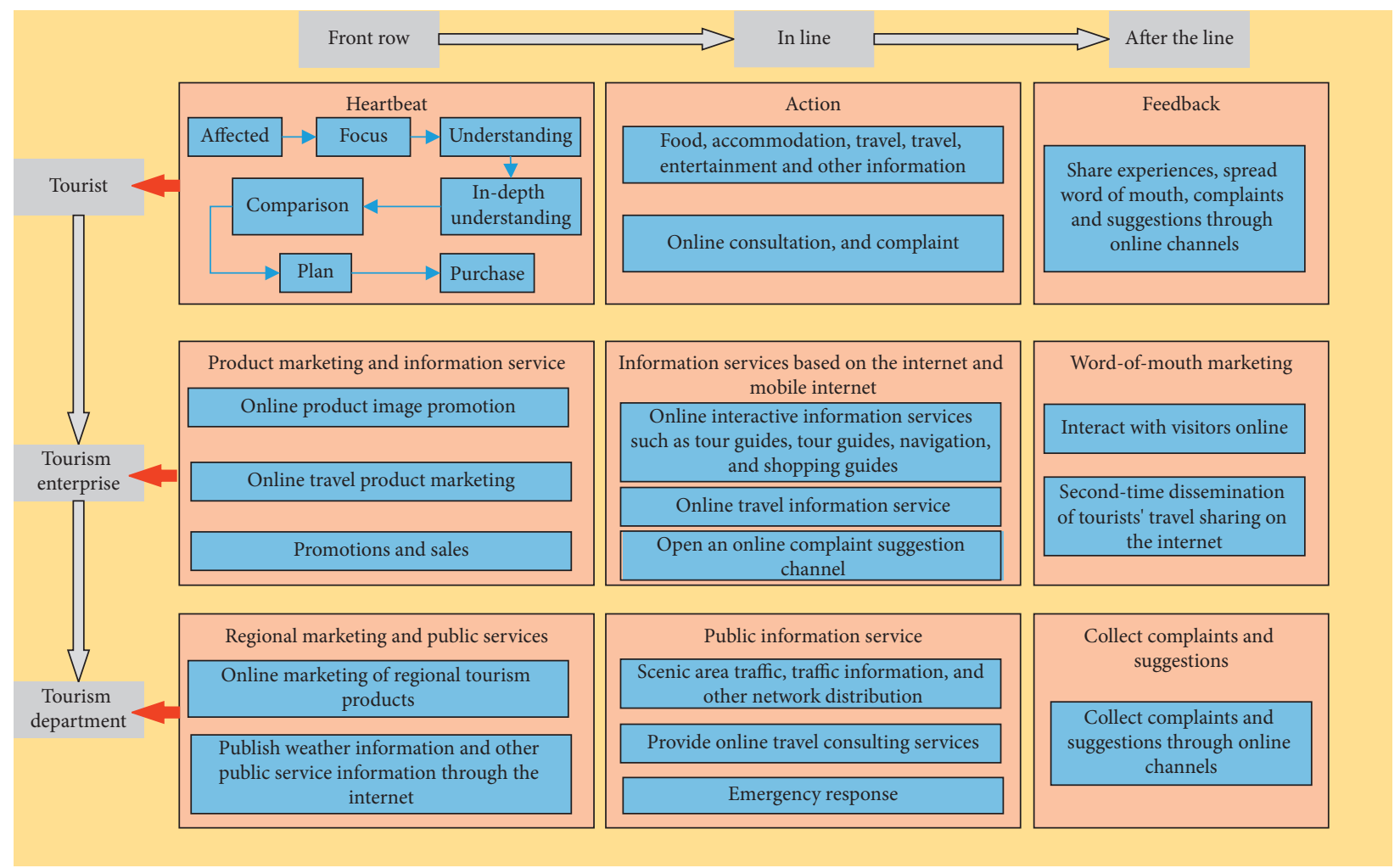

FIGURE 4: Supply-demand relationship diagram based on tourist travel behaviour.

TABLE 1: Travel methods for tourists.

\begin{tabular}{lcc}
\hline Travel mode & Number & Proportion \\
\hline Bus & 141 & 0.282 \\
Taxi & 156 & 0.311 \\
Private car & 124 & 0.215 \\
Electric car & 35 & 0.093 \\
Bicycle & 26 & 0.064 \\
Walk & 14 & 0.035 \\
\hline
\end{tabular}

$$
\begin{aligned}
\tau_{i j}(t+n) & =\rho \tau_{i j}(t)+\Delta \tau_{i j}, \\
\Delta \tau_{i j} & =\sum_{i=1}^{m} \tau_{i j}^{k} .
\end{aligned}
$$

The variable $\Delta \tau$ represents the pheromone increment left on the path by all the ants that have gone through the path $i$ to $j$ in this cycle:

$\Delta \tau_{i j}\left\{\begin{array}{l}\frac{Q}{L_{k}}, \quad \text { The } k-\text { th ant goes through path } I_{j} \text { in this cycle, } \\ 0, \quad \text { otherwise. }\end{array}\right.$

Among them, the variable $Q$ is a constant. The variable $L_{k}$ represents the length of the path taken by the $k$-th ant in this cycle.

Due to the noncontinuous nature of the design of the transportation network, it is difficult to obtain an accurate solution to this type of combinatorial optimization problem. In this paper, the ant colony algorithm with decreasing pheromone is used to optimize the bus network problem. Now, suppose that there are 6 road points A1, A2, A3, A4, A5, and A6, and the connectivity of each road point is shown in Figure 5. Among them, the distance between A6 and A3 is two, the distance between A6 and A4 is two, the distance between A 5 and A 3 is one, and the distance between A5 and A4 is one. Obviously, the distance from the road point A3 through the road point A5 to the road point A4 is smaller than the distance from the road point A6 to the road point A4. For an ant colony system with equal time intervals, it is assumed that 60 ants are placed in the ant colony system. Each ant has the same walking speed. At the same time, the concentration of pheromone released per unit time is one. For the 30 ants placed at road point A3 and road point A4, let them start at the same time and each ant chooses the walking path randomly. Suppose that 15 ants chose the A6 route to reach $\mathrm{A} 4$, and 15 ants chose the $\mathrm{A} 5$ route to reach $\mathrm{A} 4$. Since the distance of the A3-A5-A4 route is smaller than that of the A3-A6-A4, the ants who choose the A3-A5-A4 route in the same time interval arrive earlier and the pheromone concentration of the route is greater. In the case of a given waypoint, ants in the ant colony system prefer to keep the path with thicker pheromone when choosing the forward route, and the path with more pheromone means shorter "distance."

Based on the above principle, the ant colony system can find the shortest path in the road network through random 


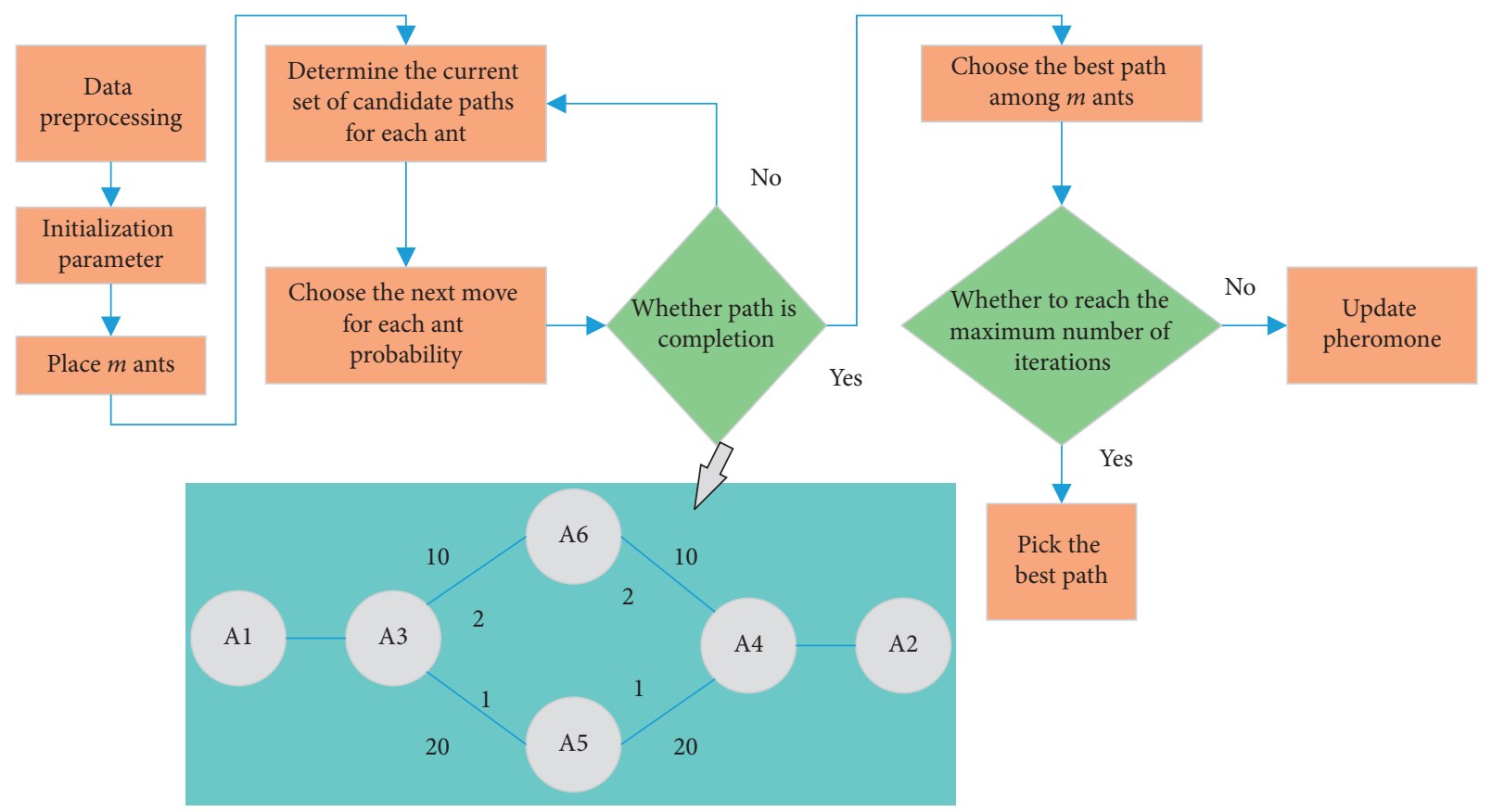

FIgURE 5: Schematic diagram of path selection.

search. The main point of the new pheromone update method is to strengthen the first half of the pheromone update range and reduce the second half of the pheromone update range during a cruise. In addition, the influence of a certain proportion of paths on the successor ants can reduce the nonoptimal search results of the predecessor ants and achieve the purpose of improving the quality of the offspring ants.

\section{Test Experiments}

4.1. Questionnaire Survey and Evaluation Criteria Design. Experts and scholars at home and abroad have conducted research on the related content and system construction of tourism public information service research. On the basis of comprehensive consideration of the principles of science, applicability, and operability, we have constructed 4 standard layers, namely, tourism network information services, tourism information consulting services, tourism logo translation services, and tourism information publicity services. They can be divided into 10 factors and 22 evaluation indicators, as shown in Table 2.

Using Likert's five-point scale method, tourists are given satisfaction based on a total of 5 points. The higher the score is, the higher the satisfaction is. The 22 questionnaires in the evaluation system are used as the object of tourist satisfaction evaluation to design questionnaires. Questionnaires were randomly distributed, 400 were returned, and 336 valid questionnaires and the questionnaire validity rate were $84 \%$. The age groups of tourists interviewed are mainly young, middle-aged, and urban residents. The education level is mainly university. The types of occupations are mainly students, enterprise management personnel and professional/cultural, educational, and scientific personnel. The age level, education level, living environment, and occupation type of the interviewees determine their certain contact and understanding of tourism activities and information technology, which is beneficial to the objectivity and reliability of the data collected in this survey. The types of tourist sources are diverse, and the gender ratio is balanced, which is conducive to the authenticity of the survey data.

It can be seen from Figure 6(a) that the travel methods of the interviewed tourists are mainly self-service and only $2.44 \%$ of the ways to participate in tour groups. It can be seen that the "free travel" travel mode has become the main travel method for domestic tourists. The construction of tourism information plays an extremely important role in "free travel" travel activities. The real-time acquisition and update of tourist information brings convenience to "free travel" tourists. On the other hand, the satisfaction evaluation of "free travel" tourists can also most directly reflect the construction and operation level of a city tourism public information service system. In the "understanding channels" option in Figure 6(b), local tourists mainly learn about the city's tourism information through other channels, online media, introductions by relatives and friends, and TV advertisements. Foreign tourists mainly obtain city information through the introduction of relatives and friends, other online media, and other channels. The above data show that with the advent of the information age, the promotion of 
TABLE 2: Evaluation model of the urban tourism public service system.

\begin{tabular}{|c|c|c|}
\hline \multicolumn{3}{|c|}{ City tourism public information service system } \\
\hline \multicolumn{2}{|c|}{ Criterion } & Factor layer \\
\hline $\begin{array}{l}\text { Tourism network } \\
\text { information service }\end{array}$ & $\begin{array}{c}\text { Travel information }(\mathrm{C} 1) \\
\text { Tourism e-commerce }(\mathrm{C} 2) \\
\text { Travel mobile information }(\mathrm{C} 3)\end{array}$ & $\begin{array}{l}\text { Website information of tourism administration website } \\
\text { Tourism enterprise portal public welfare information } \\
\text { Mobile phone and tablet network information push }\end{array}$ \\
\hline $\begin{array}{l}\text { Tourism information } \\
\text { consulting service }\end{array}$ & $\begin{array}{l}\text { Tourist information facility (C4) } \\
\text { Tourism information platform } \\
\text { (C5) }\end{array}$ & $\begin{array}{l}\text { Tourist information service centre (C41), tourist information kiosk (C42), } \\
\text { tourist information touch inquiry machine (C43), and tourist map guide } \\
\text { information service (C44) } \\
\text { Tourism service telephone (C51), telephone inquiries (C52), mobile } \\
\text { message prompt and information (C53), and other auxiliary hotlines (C54) }\end{array}$ \\
\hline $\begin{array}{l}\text { Interpretation of tourist } \\
\text { signs }\end{array}$ & $\begin{array}{l}\text { City tourism logo interpretation } \\
\text { service (C6) } \\
\text { Tourist attraction logo } \\
\text { interpretation service (C7) }\end{array}$ & $\begin{array}{l}\text { Traffic guidance sign (C61), tourist reception facility sign (C62), urban } \\
\text { environment information (C63), and public facility symbol system (C64) } \\
\text { Scenic traffic guidance sign (C71), scenic reception facility sign (C72), } \\
\text { scenic electronic display screen (C73), and self-guided tour service (C74) }\end{array}$ \\
\hline $\begin{array}{l}\text { Tourism information } \\
\text { promotion service }\end{array}$ & $\begin{array}{l}\text { Promote product }(\mathrm{C} 8) \\
\text { Propaganda media }(\mathrm{C} 9) \\
\text { Tourism public information } \\
\text { service }(\mathrm{C} 10)\end{array}$ & $\begin{array}{c}\text { Paper brochure and map } \\
\text { Radio, television, newspaper, and magazine media } \\
\text { Traffic conditions, weather information, parking information, and medical } \\
\text { information }\end{array}$ \\
\hline
\end{tabular}

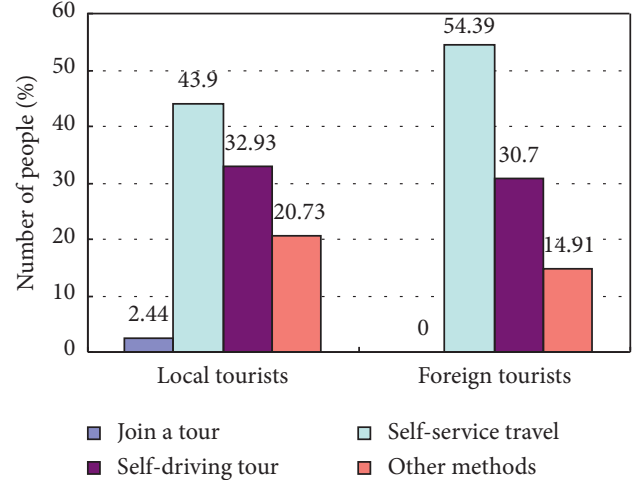

(a)

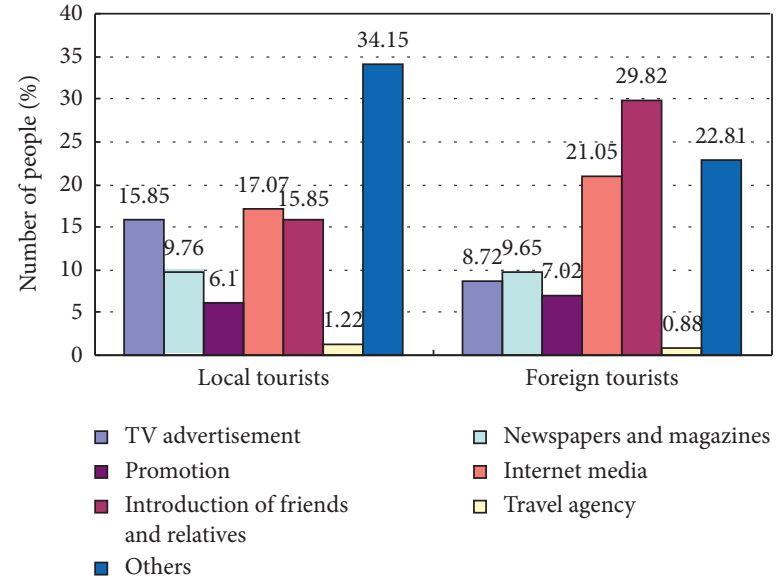

(b)

FIgURE 6: Characteristic analysis of tourist travel behaviour: (a) way of travel; (b) understanding channels.

cities through online media has become the main channel, but the high proportion of introductions by relatives and friends reflects to a certain extent the gap between the charm of the city itself and its promotional efforts. The means of information, its strength, and the degree of expansion still need to be strengthened.

\subsection{Tourists' Evaluation of the Optimized Public Service} Platform. Compare the scores of local tourists and foreign tourists horizontally, as shown in Figure 7. The scores of 22 indicators of local tourists are higher than that of foreign tourists, excluding subjective factors. The main reason is that local tourists live in the area for a long time, and they are familiar with the city's tourism information model and carrier. The time and space of exposure to tourism information services and carriers are limited, so the perception and evaluation value are relatively low. This also shows to a certain extent that the construction of Ningbo's tourism public information service system is mainly based on a static model. The dynamic and active tourism information push and service model still need to be strengthened. At present, it does not effectively serve the free travel information collection of foreign tourists. Among the evaluation values of foreign tourists, the five items with the lowest scores are tourist information kiosks, mobile text message prompts and information, mobile network information push, and tourism-consulting service centre. This also demonstrates the existence of the above problems to a certain extent.

Among the 22 indicators, the top five items with the highest evaluation values are traffic guidance signs (C61), scenic traffic guidance signs (C71), scenic reception facilities signs (C72), public facility symbol system (C64), and tourist reception facilities signs (C62). The top five 


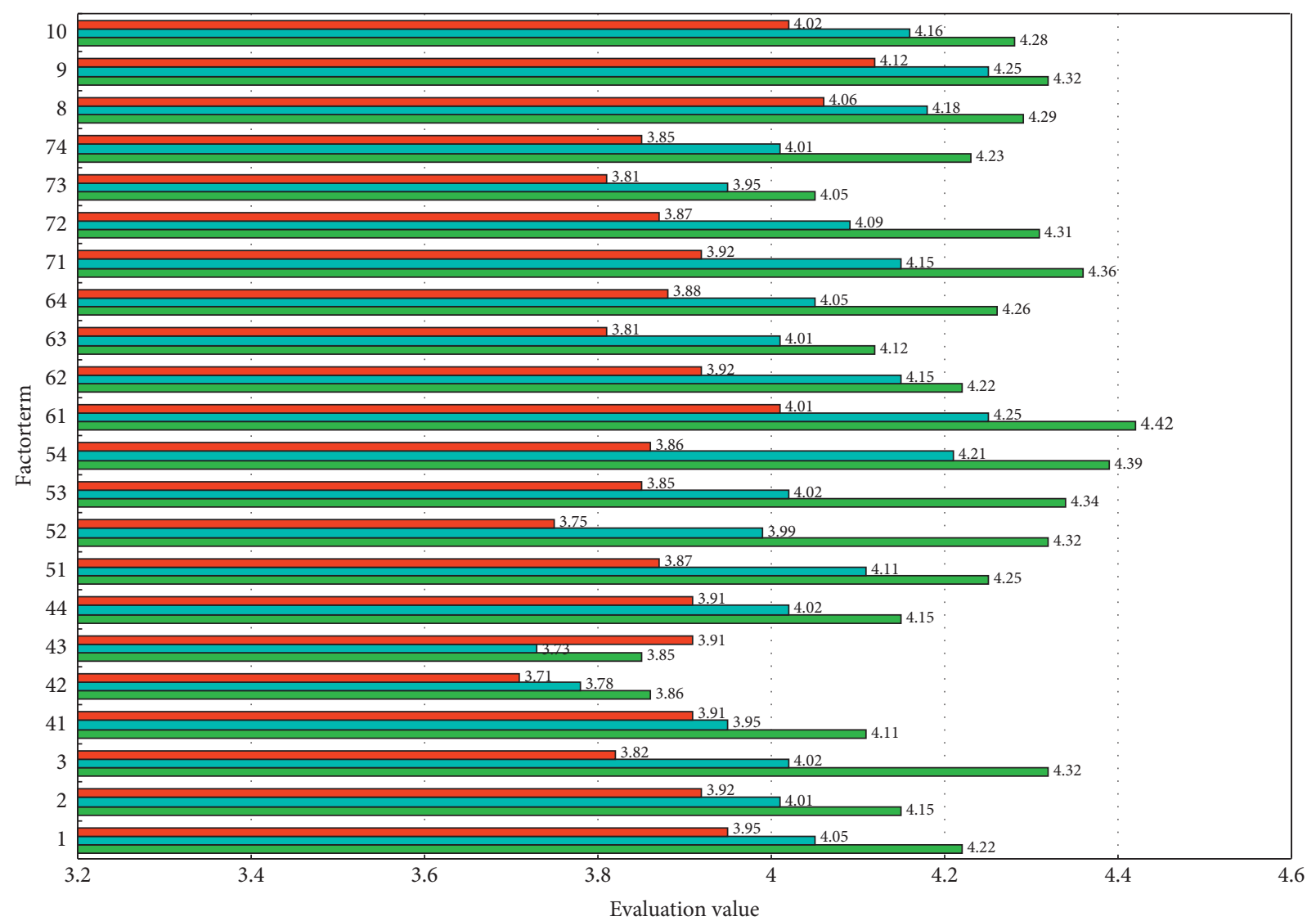

$\square$ Local tourist evaluation value

$\square$ Comprehensive evaluation value

- Evaluation value of foreign tourists

FIGURE 7: Comparison of evaluation values of different customers.

items with the lowest ratings are tourist information kiosk (C42), tourist information touch (C43), query all-in-one machine and tourist consultation service centre (C41), self-guided tour service (C74), and mobile SMS prompt and information consultation (C53). It can be seen that the relative score of tourism identification services is relatively high. Both urban public tourism service identification and scenic tourism identification construction are relatively mature, allowing tourists to obtain information in a timely manner. Information service of tourism identification is the most basic part of the tourism public information service system. However, the scores on the construction of tourism-consulting services and consulting platforms, the interpretation of tourist attractions, and the push of tourist information are relatively low, indicating that the most core and most informative features in the public tourism information service system reflect the intelligence of information technology. The tourism-consulting service still needs to be improved.

\subsection{Performance Test of Tourism Public Service Platform.} In this paper, we use pressure tools to simulate real-world concurrent requests from the client to the application server and compare the performance of the application server before and after optimization. The main indicators for evaluating server performance are the $10 \mathrm{~s}$ click rate and the corresponding response times.

It can be seen from Figure 8 that in the first $10 \mathrm{~s}$, since the number of clicks is not very large, there is not much difference before and after optimization. After $20 \mathrm{~s}$, as the number of clicks increases and the number of concurrent increases, the server before optimization is gradually unable to process requests quickly. Although the number of responses increases, the growth trend is not as fast as that of the optimized server.

It can be seen from the analysis in Figure 8 that when the server load is small, the performance of the server is not significantly improved before and after optimization. Moreover, when there are many clicks, the performance of the server will be improved by about $20 \%$.

\subsection{Analysis of the Optimization Performance of Urban} Transportation Network. In the optimization algorithm proposed in this paper, ants randomly select cities before each departure. This paper compares the ant colony algorithm with the algorithm proposed in this paper. Each algorithm is run 50 times, each run is iterated 1000 times, and 


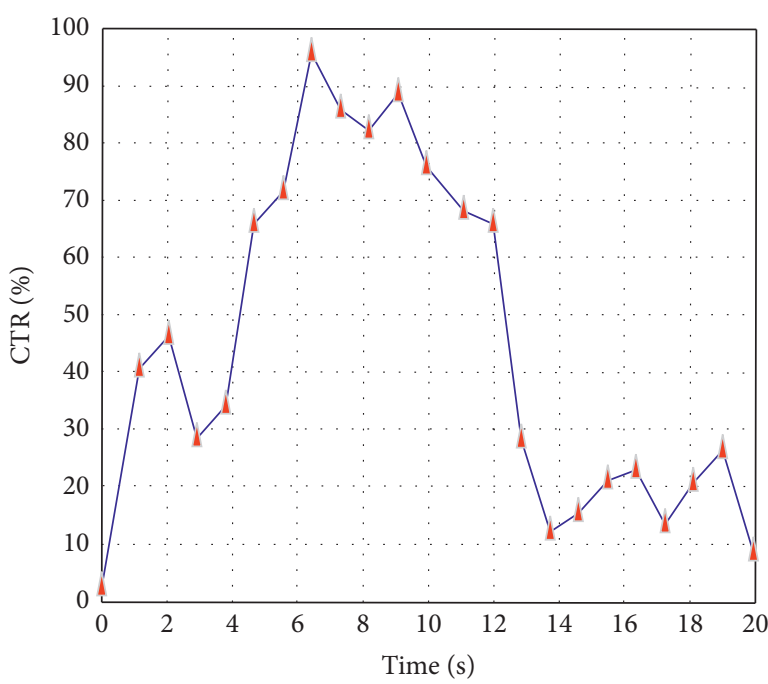

(a)

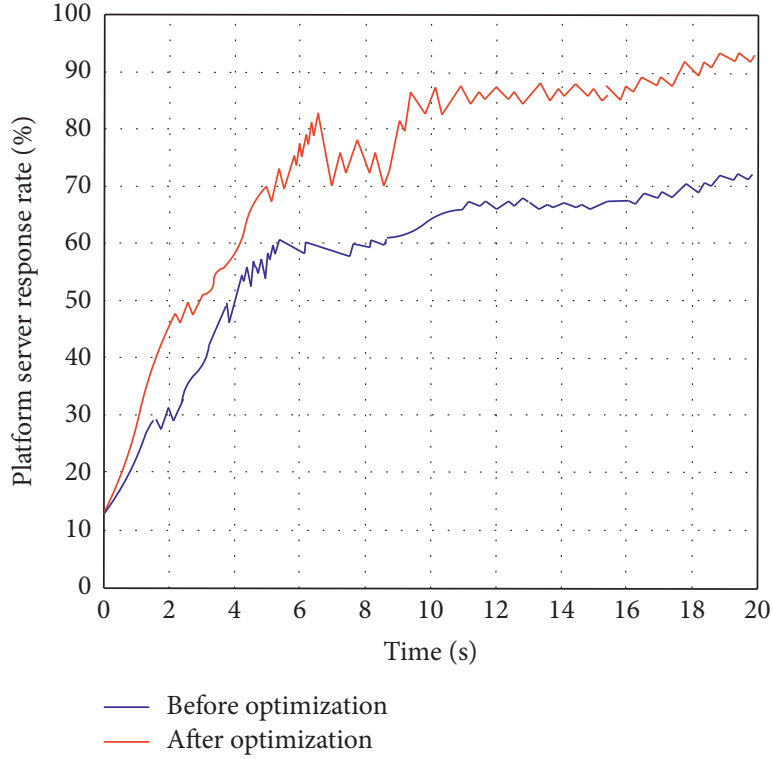

(b)

FIGURE 8: Server performance analysis of the public service platform: (a) the user clicks on the graph in each time period; (b) response graph of platform server before and after optimization.

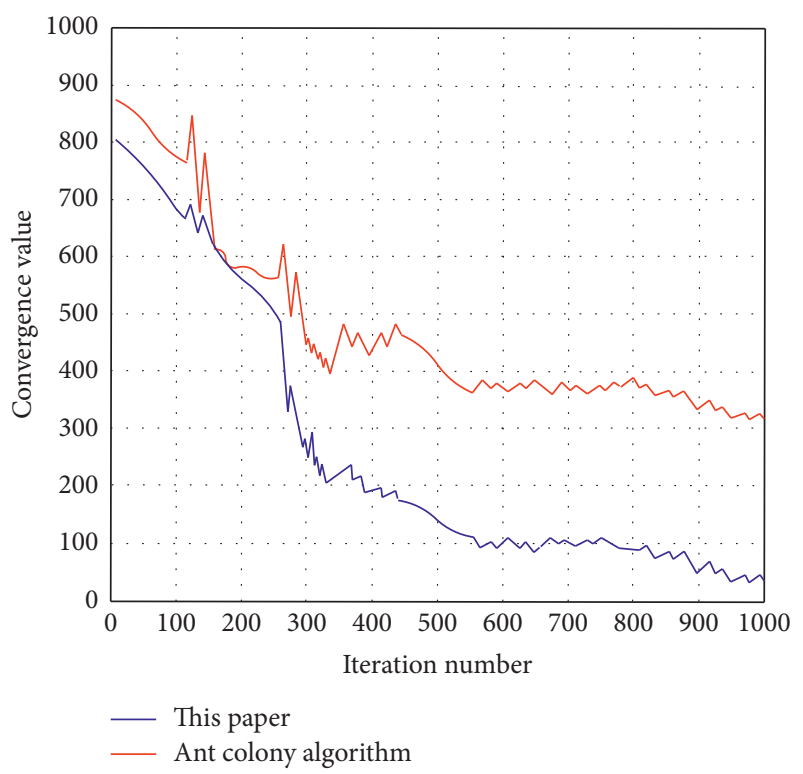

(a)

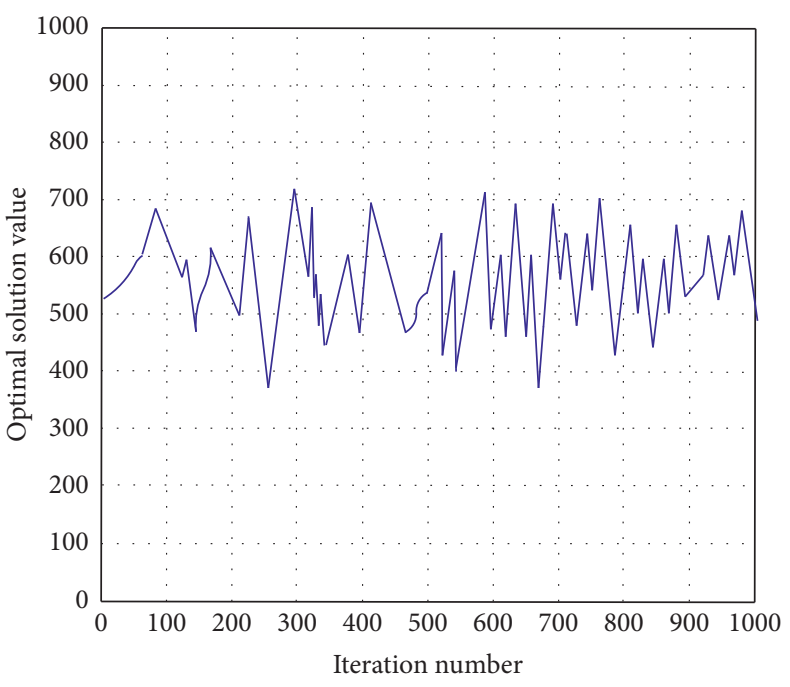

(b)

FIGURE 9: Convergence characteristics of the algorithm and diversity of solutions: (a) convergence performance of different algorithms; (b) diversity graph of the solution of this algorithm.

the best 20 sets of solutions are taken as samples. Among them, the average time is the average value of the average time to find the best solution in each run. Figure 9(a) shows a comparison result of the convergence characteristics of different algorithms. It can be seen that compared with the ant colony algorithm, the convergence of the algorithm in this paper is faster. From the experimental results of several sets of data given, the solution of the algorithm in this paper is better than that of the ant colony algorithm. In addition, from the perspective of computing time, the computing time of the algorithm in this paper is significantly shortened. Figure $9(\mathrm{~b})$ gives the solution diversity diagram, which shows that the solution diversity has been very good, has a strong search ability, can obtain the global optimal solution, 
is not easy to fall into the local optimal, and has good stability.

\section{Conclusion}

At present, there are problems in the construction of tourism public service system under the background of smart city, such as poor coordination among various departments, lack of resource integration mechanism, and low level of information of tourism public services. Using new technologies such as cloud computing and the Internet of Things, with the help of portable terminal Internet access devices, people can understand the information in time, arrange and adjust work and travel plans in time, and optimize the current public service system. Therefore, in this paper, first, we build a smart development public tourism service platform and optimize the tourism public service platform. Secondly, by focusing on the behaviour of tourists, construct a big data analysis and management system for the behaviour of smart tourism tourists. Finally, for the traffic situation in the process of tourism, a smart traffic line network based on the algorithm of pheromone ant colony is constructed. The results of the questionnaire survey on tourists show that the optimized public service system platform has achieved great satisfaction.

\section{Data Availability}

The data used to support the findings of this study are available from the corresponding author upon request.

\section{Conflicts of Interest}

The authors declare that they have no conflicts of interest.

\section{References}

[1] T. Zhang, W. Wei, X. Fu, N. Hua, and Y. Wang, "Exploring the roles of technology, people, and organization in building a tourism destination experience: insights from the 2nd USAChina tourism research summit and industry dialogue," Journal of Destination Marketing \& Management, vol. 12, pp. 130-135, 2019.

[2] S. Hua, "China's regional tourism efficiency: a two-stage double bootstrap data envelopment analysis," Journal of Destination Marketing \& Management, vol. 11, pp. 183-191, 2019.

[3] L. Larsson and D. K. Müller, "Coping with second home tourism: responses and strategies of private and public service providers in Western Sweden," Current Issues in Tourism, vol. 22, no. 16, pp. 1958-1974, 2019.

[4] C. Bassano, S. Barile, P. Piciocchi, J. Spohrer, F. Iandolo, and R. Fisk, "Storytelling about places: tourism marketing in the digital age," Cities, vol. 87, pp. 10-20, 2019.

[5] I. G. A. K. R. Spohrer, Z. O. Jainah, L. A. Marpaung et al., "Juridical analysis of natural resource conservation in the development of Pahawang Island Lampung tourism area based on local wisdom in Indonesia," Journal of Environmental Management and Tourism, vol. 10, no. 5, pp. 11451149, 2019.

[6] S. Fatimah and D. Ramadhan, "Sustainable tourism integrated tourism area based on culture and local wisdom at Mandeh area," International Journal of Tourism, Heritage and Recreation Sport, vol. 1, no. 1, pp. 1-7, 2019.

[7] H. San Martín, A. Herrero, and M. d. M. García de los Salmones, "An integrative model of destination brand equity and tourist satisfaction," Current Issues in Tourism, vol. 22, no. 16, pp. 1992-2013, 2019.

[8] F. Ahmadimanesh, M. M. Paydar, and E. Asadi-Gangraj, "Designing a mathematical model for dental tourism supply chain," Tourism Management, vol. 75, pp. 404-417, 2019.

[9] Y. Li, C. Hu, C. Huang, and L. Duan, "The concept of smart tourism in the context of tourism information services," Tourism Management, vol. 58, pp. 293-300, 2017.

[10] X. Duan, "Smart tourism based on Internet of Things," Revista de la Facultad de Ingenieria, vol. 32, no. 10, pp. 66-170, 2017.

[11] W. Zhang, G. Tan, and C. Sun, "Design and development of an intelligent tourist guide system," Journal of Geomatics, vol. 43, no. 5, pp. 79-84, 2018.

[12] H. Zhu, X. Li, and X. Lin, "Infrastructure smart service system (iS3) and its application," China Civil Engineering Journal, vol. 51, no. 1, pp. 1-12, 2018.

[13] C. Li, X. Yuan, W. Sun, and X. Liu, "Research of directory service model for geographic information," Journal of Geographic Information System, vol. 10, no. 4, pp. 476-489, 2018.

[14] W. K. Liu, "From fantasy to reality: a study of pre-trip planning from the perspective of destination image attributes and temporal psychological distance," Service Business, vol. 12, no. 4, pp. 1-20, 2018.

[15] C. Zhou, Z. Weng, C. Xu, and Z. Su, "Integrated traffic information service system for public travel based on smart phones applications: a case in China," International Journal of Intelligent Systems and Applications, vol. 5, no. 12, pp. 72-80, 2013.

[16] H. Su, X. Ji, and C. Feng, "The empirical research on information behavior characteristics and satisfaction of drivers based on smart phone," Procedia Engineering, vol. 137, pp. 343-351, 2016.

[17] J. Shen, J. Shen, T. Mei, and X. Gao, "Landmark reranking for smart travel guide systems by combining and analyzing diverse media," IEEE Transactions on Systems, Man, and Cybernetics: Systems, vol. 46, no. 11, pp. 1492-1504, 2016.

[18] A. Andersson, L. Winslott Hiselius, and E. Adell, "Promoting sustainable travel behaviour through the use of smartphone applications: a review and development of a conceptual model," Travel Behaviour and Society, vol. 11, pp. 52-61, 2018.

[19] Y. Shigematsu, S. Aikawa, and Y. Nakamura, "An empirical study on the compose method of outdoor/indoor position estimation," IEEJ Transactions on Electronics, Information and Systems, vol. 138, no. 2, pp. 140-148, 2018.

[20] R. Montealegre and W. F. Cascio, "Technology-driven changes in work and employment," Communications of the ACM, vol. 60, no. 12, pp. 60-67, 2017.

[21] F. Mehraliyev, I. C. C. Chan, Y. Choi, M. A. Koseoglu, and R. Law, "A state-of-the-art review of smart tourism research," Journal of Travel \& Tourism Marketing, vol. 37, no. 1, pp. 78-91, 2020.

[22] P. Koseoglu and R. Kitchin, "Being a 'citizen' in the smart city: up and down the scaffold of smart citizen participation in Dublin, Ireland," GeoJournal, vol. 84, no. 1, pp. 1-13, 2019.

[23] N. Komninos, C. Bratsas, C. Kakderi et al., "Smart city ontologies: improving the effectiveness of smart city applications," Journal of Smart Cities, vol. 1, no. 1, pp. 31-46, 2019.

[24] A. Caragliu and C. F. Del Bo, "Smart innovative cities: the impact of smart city policies on urban innovation," 
Technological Forecasting and Social Change, vol. 142, pp. 373-383, 2019.

[25] I. Yaqoob, I. A. T. Hashem, A. Ahmed, S. M. A. Kazmi, and C. S. Hong, "Internet of things forensics: recent advances, taxonomy, requirements, and open challenges," Future Generation Computer Systems, vol. 92, pp. 265-275, 2019.

[26] Z. Kazmi and J.-H. Lee, "Mobility capability negotiation for IPv6 based ubiquitous mobile internet," Computer Networks, vol. 157, pp. 24-28, 2019. 